\title{
Distortions of the magnetic field by storm-time current systems in Earth's magnetosphere
}

\author{
N. Yu. Ganushkina ${ }^{1,2}$, M. W. Liemohn ${ }^{1}$, M. V. Kubyshkina ${ }^{3}$, R. Ilie ${ }^{1}$, and H. J. Singer ${ }^{4}$ \\ ${ }^{1}$ Department of Atmospheric, Oceanic and Space Sciences, University of Michigan, Ann Arbor, MI, USA \\ ${ }^{2}$ Finnish Meteorological Institute, Helsinki, Finland \\ ${ }^{3}$ Institute of Physics, University of St. Petersburg, St. Petersburg, Russia \\ ${ }^{4}$ NOAA Space Environment Center, Boulder, CO, USA
}

Received: 11 August 2009 - Revised: 6 November 2009 - Accepted: 17 December 2009 - Published: 18 January 2010

\begin{abstract}
Magnetic field and current system changes in Earth's inner magnetosphere during storm times are studied using two principally different modeling approaches: on one hand, the event-oriented empirical magnetic field model, and, on the other, the Space Weather Modeling Framework (SWMF) built around a global MHD simulation. Two storm events, one moderate storm on 6-7 November 1997 with Dst minimum about $-120 \mathrm{nT}$ and one intense storm on 21-23 October 1999 with Dst minimum about $-250 \mathrm{nT}$ were modeled. Both modeling approaches predicted a large ring current (first partial, later symmetric) contribution to the magnetic field perturbation for the intense storm. For the moderate storm, the tail current plays a dominant role in the eventoriented model results, while the SWMF results showed no strong tail current in the main phase, which resulted in a poorly timed storm peak relative to the observations. These results imply that the the development of a ring current depends on a strong force to inject the particles deep into the inner magnetosphere, and that the tail current is an important external source for the distortions of the inner magnetospheric magnetic field for both storms. Neither modeling approach was able to reproduce all the variations in the $B_{x}$ and $B_{y}$ components observed at geostationary orbit by GOES satellites during these two storms: the magnetopause current intensifications are inadequate, and the field-aligned currents are not sufficiently represented. While the event-oriented model reproduces rather well the $B_{z}$ component at geostationary orbit, including the substorm-associated changes, the SWMF field is too dipolar at these locations. The empirical model is a useful tool for validation of the first-principle based models such as the SWMF.
\end{abstract}

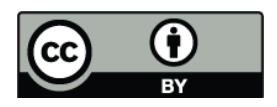

Correspondence to: N. Yu. Ganushkina (natalia.ganushkina@fmi.fi)
Keywords. Magnetospheric physics (Current systems; Magnetospheric configuration and dynamics; Storms and substorms)

\section{Introduction}

During geomagnetic storms the near-Earth magnetic field exhibits changes over a wide range of spatial and temporal scales and becomes highly distorted from its typical, quiettime, dipolar configuration (e.g., Parker and Stewart, 1967; Tsyganenko et al., 2003). Tsyganenko et al. (2003) found that for intense storms with Dst about $-250 \mathrm{nT}$, the taillike deformation of dipole fields can penetrate to distances as small as $3-4 R_{\mathrm{E}}$. The distortion is not uniform, however, and is a strong function of the intensity and location of the magnetospheric current systems. Current systems responsible for these distortions include: (a) the cross-tail current in the near-Earth plasma sheet that stretches field lines on the nightside, (b) the partial ring current that bulges out the field in some localized regions across the evening and nightside, (c) the Chapman-Ferraro magnetopause currents that compress the dayside magnetic field, (d) the various field-aligned currents that twist the field lines in their local neighborhood, and (e) the symmetric ring current that inflates the entire inner magnetospheric field. All of these processes lead to numerous space weather effects, such as, for example, the radial expansion of relativistic electron drift paths in the outer radiation belt.

Deconvolving the magnetic field distortion into the original current systems is a complicated problem. It is very difficult to separate the contributions from different current systems based only on point magnetic field measurements taken both in space and on the ground. A global magnetospheric

Published by Copernicus Publications on behalf of the European Geosciences Union. 
magnetic field model is needed to address the question regarding which of the current systems is responsible for what effects in the inner magnetospheric field distortion during storms.

Several studies have been devoted to the development of general-purpose, global empirical magnetic field models (e.g., Tsyganenko, 1995, 2002; Tsyganenko and Sitnov, 2005, 2007; Hilmer and Voigt, 1995; Alexeev et al., 2001). If the current in the model can be specified in a manner that is consistent with plasma flow through the magnetosphere, then the resulting magnetic field topology can be realistic. The problem, however, is that such a statistical field is often inconsistent with temporally changing magnetic field observations. While useful for a variety of applications, such statistical models cannot account for the details of the magnetic field variations during storms and substorms, i.e., under conditions that are also key for space weather applications.

A time-evolving empirical model called "event-oriented model" for the terrestrial inner magnetosphere magnetic field was developed by Ganushkina et al. (2002, 2004). Based on in-situ observations of the magnetospheric magnetic field, the model adjusts a statistical solution to give a global representation of the magnetic field evolution for that specific storm event. The main advantage of this event-oriented model is its ability to reproduce both the larger-scale and smaller-scale variations of the magnetic field during storms and substorms. This model has been used to successfully model sawtooth events (Pulkkinen et al., 2006; Kubyshkina et al., 2008) with characteristic sawtooth-type variations of magnetic field and particle fluxes observed at geosynchronous orbit.

Another way to obtain the magnetic field in the magnetosphere is from MHD modeling. Several MHD models for the global magnetosphere exist including, (1) the BlockAdaptive-Tree-Solar wind-Roe-Upwind-Scheme (BATS-RUS) (Powell et al., 1999) and (2) the Lyon-FedderMobarry (LFM) codes (Lyon et al., 2004), which both can be combined with the Rice Convection Model (RCM) (Wolf, 1978; Toffoletto et al., 2003), (3) the GUMICS (Grand Unified Magnetosphere-Ionosphere Coupling Simulation) code (Janhunen, 1996) developed and operated by the Finnish Meteorological Institute, (4) the global, self-consistent, fully electrically coupled magnetosphereionosphere-thermosphere model by Raeder et al. (2001). The proper representation of the inner magnetosphere in global MHD by coupling with inner magnetosphere/ring current/radiation belt models is an important, but still open issue, which is under intense investigation at present.

Several recent studies have shown that the magnetic field choice can alter the total energy content of the ring current by up to a factor of two (a more stretched field decreases the plasma content) (e.g., Lemon et al., 2004; Ganushkina et al., 2005, 2006; Zaharia et al., 2005, 2006; Chen et al., 2006). De Zeeuw et al. (2004) showed that the magnetic field configuration is altered by the presence of a ring current in the inner magnetosphere even in the global scale: the tail is stretched by the presence of a stronger ring current, and the neutral line is moved backward. A consistent feature of global MHD models without this kinetic-model coupling is that the stormtime inner magnetospheric field is under-stretched (e.g., De Zeeuw et al., 2004; Huang et al., 2006). The implication of these results is that realistic models of the inner magnetosphere must include a self-consistent description of the ring current (Zaharia et al., 2006).

Usually, in the ring current models the outer boundary is set at $6.6 R_{\mathrm{E}}$, where plasma density and temperature observations are available from the LANL satellites (Bame et al., 1993). These measurements can then be used to determine the boundary conditions in the plasma sheet (Jordanova, 2001; Liemohn et al., 2001; Ganushkina et al., 2006). The particles inside geostationary orbit are identified as the ring current particles. It is now accepted that the storm-time ring current is usually not a ring at all, but rather a partial (asymmetric) ring, especially in the main phase and early recovery phase of storms (Liemohn et al., 2001; Mitchell et al., 2001; Pollock et al., 2001). Several studies have shown large asymmetries in magnetic field and particle data of the inner magnetosphere (Lui, 2003; Le et al., 2004; Jorgensen et al., 2004).

On the other hand, contributions from the tail current are usually not considered. The availability of magnetospheric magnetic field models made it possible to study the evolution of current systems during geomagnetic storms and to estimate their relative contributions to the Dst index (Ganushkina et al., 2004; Kalegaev et al., 2005). By modeling several storm events, Ganushkina et al. (2004) have shown that the tail current intensifies first and tracks the drop in the Dst index. The ring current develops more slowly, and then stays at an increased level longer than the tail current. During moderate storms (Dst about $-150 \mathrm{nT}$ ), both ring and tail currents are intensified, the tail current contributes more to Dst than the ring current. On the other hand, during intense storms (Dst $<-200 \mathrm{nT}$ ), the tail current is intensified, and remains nearly constant, while the ring current follows the Dst variations. Thus, the information contained in the Dst index is different during small and large storms.

Although analysis of contributions to the Dst index tells us about the behavior of current systems, the question which remains still unanswered is what current systems are responsible for which aspects of the storm-time magnetic field distortion and in which magnetospheric region. It is prudent to address this topic with several numerical models, comparing the results with data and with each other, in order to obtain a physically consistent, realistic, and accurate global magnetic field topology. In this study we will compare the eventoriented empirical magnetic field model developed in earlier studies (Ganushkina et al., 2002, 2004) with the models included in the Space Weather Modeling Framework (SWMF) (Toth et al., 2005). In addition, the Tsyganenko and Sitnov TS04 (Tsyganenko and Sitnov, 2005) magnetic field model is 
used as a reference model. We present results for two storms, one moderate on 6-7 November 1997 with Dst minimum of -120 nT, and one intense on 21-23 October 1999 when Dst reached to $-250 \mathrm{nT}$. Both storm events were previously modeled with the event-oriented model (Ganushkina et al., 2004; Kalegaev et al., 2005). The new aspect of this study is that we use two principally different modeling approaches, the event-oriented empirical magnetic field model and the models in the Space Weather Modeling Framework (SWMF). We perform detailed numerical simulations, data-model comparisons, and model-model comparisons in order to understand the current systems that lead to inner magnetosphere magnetic field distortions and to identify the fundamental physical processes leading to these magnetic configurations. In particular, we will consider the importance of the tail current for the accurate representation of the inner magnetosphere magnetic field, and how the empirical models can be used to validate the SWMF models.

\section{Modeling approaches}

We use and compare two approaches to produce the magnetic field in Earth's magnetosphere, namely, the event-oriented empirical model and MHD simulation. A third model, the Tsyganenko and Sitnov TS04 model (Tsyganenko and Sitnov, 2005) is used to show how this global and widely used model is able to represent the magnetic field variations during storm times. However, analyzing the accuracy of the TS04 model is not the goal of this paper.

\subsection{Event-oriented empirical magnetospheric magnetic field model}

The event-oriented model has been used to analyze a number of storm-time events and has been discussed in detail by Ganushkina et al. (2004). The basic approach is to begin with the statistical field model given by the $\mathrm{T} 89$ model for $\mathrm{Kp}=4$ (Tsyganenko, 1989), and to modify the existing current systems and to add storm time current components to the model to obtain a best fit to all available high-altitude magnetic field measurements as well as the ground-based Dst index.

The original ring current in T89 was replaced by a stormtime ring current module (Ganushkina et al., 2002). This ring current module contains two symmetric currents, one flowing eastward closer to Earth and one flowing westward further away from the Earth, and an asymmetric ring current. Both symmetric ring current intensities are given by

$J\left(\mathbf{r}, \frac{B}{B_{0}}\right)=J_{0} \exp \left(-\frac{\left(r_{\mathrm{eq}}-r_{0}\right)^{2}}{2 \sigma^{2}}\right)\left(\frac{B}{B_{0}}\right)^{-A / 2}$,

where $B_{0}$ is the magnetic field at the equator, $J_{0}$ is the maximum current density, $r_{0}$ is the radial location of the maximum current density, $\sigma$ is the current distribution width in the radial direction, and $A$ is the anisotropy index determining how concentrated the current is close to the equatorial plane.

The asymmetric partial ring current, $J_{\mathrm{PART}}$, is modeled by a function similar to the symmetric ring current, but with an additional asymmetry factor given by $(1-\cos (\phi-\delta))$, where $\phi$ is the azimuth angle and $\delta$ is the duskward shift angle giving the azimuthal location of the current maximum. The asymmetry factor gives rise to field-aligned currents in the region 2 sense.

With this formulation, the ring current module includes eight free parameters: The radial distances of maximum current densities of the eastward and westward symmetric ring currents and the asymmetric partial ring current $\left(R_{0, \mathrm{EAST}}, R_{0, \mathrm{WEST}}, R_{0, \mathrm{PART}}\right)$, maximum current densities $\left(J_{0, \text { EAST }}, J_{0, \text { WEST }}, J_{0, \text { PART }}\right)$, current distribution width $(\sigma)$, and anisotropy index (A), both of which are the same for all three current systems. As the duskward shift $\delta$ of the partial ring current is known to depend on the level of magnetic activity, it is evaluated from the Dst index (see Tsyganenko, 2002) as

$\delta=\frac{\pi}{2} \tanh \frac{|\mathrm{Dst}|}{40}$.

We account for the magnetotail current intensification by modifying the T89 tail current intensity by a factor $(1+$ ATS), where ATS is a constant determining the increase (positive values) or decrease (negative values) from the baseline T89 model. In addition to modifying the intensity of the entire tail current, we add a new current sheet with an intensity $A_{\mathrm{NTC}}$, which represents the substorm-associated thin current sheet forming near the inner edge of the tail current sheet. The new tail current sheet is formulated using vector potentials to ensure that the magnetic field remains divergenceless. For details of the formulation we refer to Tsyganenko (1989) and Ganushkina et al. (2002, 2004). The tail current formulation includes five free parameters: Current intensities ATS and $A_{\mathrm{NTC}}$, earthward and tailward edge locations of the new thin current sheet $X_{1, \mathrm{NTC}}$ and $X_{2, \mathrm{NTC}}$, and half-thickness of the thin current sheet $D_{0}$.

As the T89 model does not include an explicit magnetopause in its electric current formulation, modification of the model currents is not as straight-forward as in the case of the intramagnetospheric currents. We thus scale the T89 magnetopause field components by a time-varying constant AMP $=\sqrt{\left(P_{\mathrm{SW}} / 2 \mathrm{nPa}\right)}$. In addition to scaling the dayside Chapman-Ferraro currents, it is also necessary to scale the characteristic scale size of the magnetotail. We scale the tail radius to match that given by Shue et al. (1998). The magnetopause currents and the magnetotail radius are then defined by the observed solar wind and IMF parameters in the form

$B_{\mathrm{CF}}=\left(\frac{P_{\mathrm{SW}}}{2 \mathrm{nPa}}\right)^{\frac{1}{2}} B_{\mathrm{CF}_{\mathrm{T} 89}, R_{\mathrm{T}}}=\left(\frac{Z_{\mathrm{T}, \text { Shue }}}{Z_{\mathrm{T}, \mathrm{T} 89}}\right) R_{\mathrm{T}, \mathrm{T} 89}$ 
where $R_{\mathrm{T}}=30 R_{\mathrm{E}}$ is the $\mathrm{T} 89$ tail radius value for $\mathrm{Kp}=4$. The magnetopause position $Z$-coordinates are evaluated from the Shue et al. (1998) model $\left(Z_{\mathrm{T}, \text { Shue }}\right)$ and T89 model $\left(Z_{\mathrm{T}, \mathrm{T} 89}\right)$ at $X=-20 R_{\mathrm{E}}$ and $Y=0$. The magnetopause current modeling involves only two parameters (AMP and $R_{\mathrm{T}}$ ), both of which are directly determined from solar wind and IMF observations.

\subsection{Magnetic field from SWMF}

The Space Weather Modeling Framework (SWMF) is a robust numerical tool for heliophysical simulations, providing a high-performance computational capability to simulate the physics from the solar surface to the upper atmosphere of Earth (Toth et al., 2005). The SWMF integrates and couples models for various physics domains with a model solving the physics within each domain. Two-way coupling of these codes results in a self-consistent model. In this paper the calculations were made using three geospace domains of SWMF, namely, the Global Magnetosphere (GM), Inner Magnetosphere (IM), Ionospheric Electrodynamics (IE).

Global Magnetosphere (GM) domain describes the magnetic field and plasma properties in the outer magnetosphere. There is one model for the global magnetosphere in the SWMF, the Block Adaptive Tree Solar-wind-type Roe Upwind Scheme (BATSRUS) global magnetohydrodynamic (MHD) model (Powell et al., 1999; Gombosi et al., 2002). The Inner Magnetosphere (IM) domain solves the energydependent particle flows of hot ions and electrons. The SWMF includes the Rice Convection Model (RCM) (Jaggi and Wolf, 1973; Harel et al., 1981; De Zeeuw et al., 2004). In the domain of Ionospheric Electrodynamics (IE) twodimensional electric potential and auroral precipitation patterns are described. The SWMF uses the Ridley Ionosphere Model (RIM), which is a combination of an electric potential solver and a model of the electron precipitation (Ridley and Liemohn, 2002; Ridley et al., 2004), and which is needed for proper GM and IM domain simulations.

For this study, the inner boundary of GM module was set at $2.5 R_{\mathrm{E}}$ from the center of the Earth, where the flows generated by the ionospheric potential are set. The simulation domain is defined by $X_{\mathrm{gsm}}$ ranging from [ $\left.-224 R_{\mathrm{E}}, 32 R_{\mathrm{E}}\right]$, with $Y_{\mathrm{gsm}}$ and $Z_{\mathrm{gsm}}$ ranging from $\left[-128 R_{\mathrm{E}}, 128 R_{\mathrm{E}}\right]$. The measurements of the magnetic field, velocity, density and temperature from the ACE satellite were used as the upstream conditions. The IM domain overlaps with the GM domain and changes according to the open/closed field line boundary information provided by BATSRUS. The IM domain typically extends to $10 R_{\mathrm{E}}$ in $X_{\mathrm{gsm}}$ and $Y_{\mathrm{gsm}}$ coordinates in the equatorial plane, within the GM region. We ran the model with refined spatial resolution, the smallest being set to $1 / 8 \mathrm{Re}$ in the shell region from 2.5 to $3.5 \mathrm{Re}$, and close to the Earth $\left(X_{\mathrm{gsm}}: 16 R_{\mathrm{E}},-32 R_{\mathrm{E}}, Y_{\mathrm{gsm}}:-8 R_{\mathrm{E}}, 8 R_{\mathrm{E}}\right.$, $Z_{\mathrm{gsm}}:-8 R_{\mathrm{E}}, 8 R_{\mathrm{E}}$ ) the resolution was set to $1 / 4 R_{\mathrm{E}}$. Close to the tail and bow shock the resolution was set to $1 / 2 R_{\mathrm{E}}$, while everywhere else it was $2 R_{\mathrm{E}}$. Coupling the three components enables passing information back and forth between the GM, IE and IM. The IM module obtains the field topology and plasma information from the GM component, while getting the electric potential from the IE, and provides the density and pressure corrections back to GM every $10 \mathrm{~s}$. The IM-GM and IE-IM couplings were set to $10 \mathrm{~s}$ ( 2 time steps in RCM). The GM and IE components are coupled every $5 \mathrm{~s}$, meaning that the electric potential from IE and the field aligned currents from GM are updated at this frequency. Typically, each simulation domain contains about 2.5 million cells and a BATSRUS time step of $0.7 \mathrm{~s}$ (RCM has a $5 \mathrm{~s}$ time step).

In the following analysis, the SWMF is run for the same events with the same upstream solar wind conditions as the event-oriented magnetic field model. The magnetic field results are specifically from the BATSRUS MHD model within the SWMF, but note that these fields have been modified by the two-way coupling with the IM and IE modules. Without the inclusion of the IM energy-dependent drift physics, the MHD magnetic fields in the inner magnetosphere are highly dipolar and the near-Earth currents are very low, even during large solar wind driving conditions (e.g., De Zeeuw et al., 2004; Zhang et al., 2007). The two-way coupling between the GM and IM modules is absolutely necessary for the creation of a realistic magnetic distortion of the inner magnetosphere. Below, we will refer to the magnetic field results from this model as SWMF field results, even though they are extracted from a specific module within the SWMF.

\section{Overview of modeled storm events: 6-7 November 1997 and 21-23 October 1999}

Two storm events which have been previously modeled with the event-oriented model were selected for the present study. Figure 1 presents an overview of the magnetic storms on 6-7 November 1997 and 21-23 October 1999. The solar wind and IMF data were obtained from the Wind spacecraft and are shown with about 40 min time shift for propagation to Earth's magnetopause.

A moderate intensity storm occurred on 6-7 November 1997 (Fig. 1a). On 6 November $B_{z}$ fluctuated around zero and dropped to $-15 \mathrm{nT}$ at the end of the day around 23:00 UT. On 6 November, the solar wind dynamic pressure was about $3 \mathrm{nPa}$, increasing up to about $10 \mathrm{nPa}$ at about 22:00 UT. The AE index had several peaks with highest magnitude about $1000 \mathrm{nT}$ at the beginning of 7 November. Dst reached $-120 \mathrm{nT}$ at about 04:00 UT on 7 November and recovered to $-20 \mathrm{nT}$ by the end of the day.

Figure $1 \mathrm{~b}$ shows an overview of the intense storm on $21-$ 23 October 1999. IMF $B_{z}$ turned from $+20 \mathrm{nT}$ to $-20 \mathrm{nT}$ at about 23:50 UT on 21 October and after some increase during the next three hours dropped to $-30 \mathrm{nT}$ around 06:00 UT on 22 October. After that, the IMF $B_{z}$ oscillated around zero. Solar wind dynamic pressure showed two main peaks, 

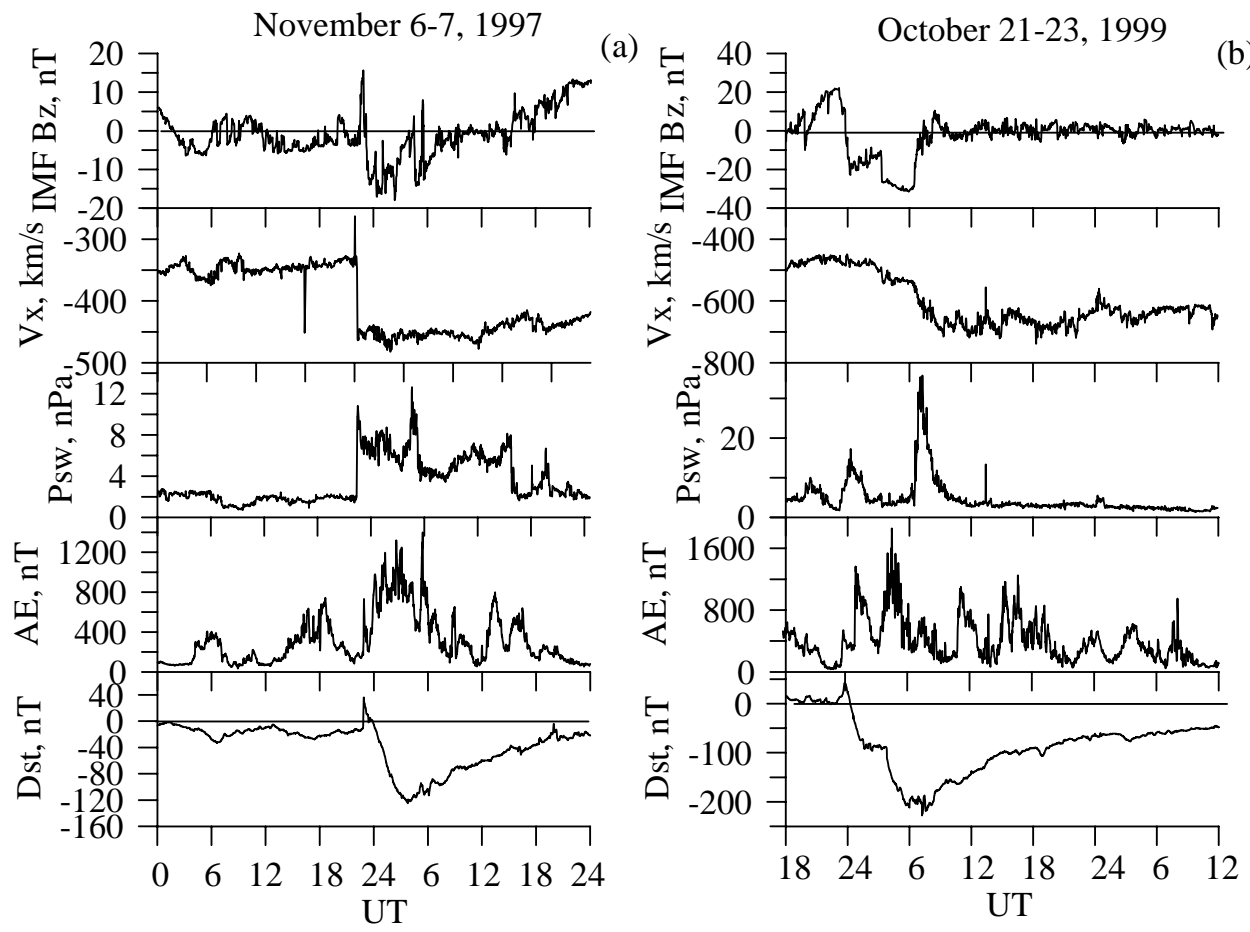

Fig. 1. Overview of the magnetic storms on (a) 6-7 November 1997 and (b) 21-23 October 1999. The solar wind and IMF data were obtained from Wind spacecraft taking into account the time shift of about $40 \mathrm{~min}$.

a $15 \mathrm{nPa}$ peak around 24:00 UT on 21 October and a $35 \mathrm{nPa}$ peak around 07:00 UT on 22 October. There were several peaks in the AE index reaching 800-1600 nT. The Dst index dropped to $-230 \mathrm{nT}$ at 06:00-07:00 UT on 22 October.

Figure 2 shows the satellite locations for GOES 8 (blue), GOES 9 or 10 (red), Polar (green), Geotail (orange) and Interball Tail (purple), in the equatorial and noon-midnight meridian planes, during (a) 00:00-10:00 UT on 7 November 1997 and (b) 00:00-12:00 UT on 22 October 1999, which correspond to the storm main phase and early recovery phase. The time interval between two dots on the satellite orbits is $1 \mathrm{~h}$. Both events had quite comprehensive satellite coverage within the magnetosphere.

During the November 1997 storm both GOES satellites were moving from the duskside to the nightside. Polar was almost in the noon-midnight meridian plane above the equatorial plane $\left(Z_{\mathrm{gsm}}\right.$ from about 8 to $\left.2 R_{\mathrm{E}}\right)$, entering from the nightside $\left(X_{\mathrm{gsm}}\right.$ about $\left.-6 R_{\mathrm{E}}\right)$ to the dayside $\left(X_{\mathrm{gsm}}\right.$ about $2 R_{\mathrm{E}}$ ). In addition, measurements were available from the Interball Tail probe, which was moving Earthward from the magnetotail below the equatorial plane $\left(Z_{\mathrm{gsm}}\right.$ about $\left.-9 R_{\mathrm{E}}\right)$ on the dawnside $\left(Y_{\mathrm{gsm}}\right.$ about $\left.-8 R_{\mathrm{E}}\right)$.

For the October 1999 storm measurements from 5 satellites were available. GOES 8 was on the nigthside moving towards dawn. GOES 10 was entering the nightside from the duskside. Polar passed its apogee at $9 R_{\mathrm{E}}$ in the tail moving from dawn to dusk rising above the equatorial plane.
Part of the Interball Tail probe orbit contained its perigee on the dayside, the spacecraft entered from below the equatorial plane $\left(Z_{\mathrm{gsm}}\right.$ about $\left.-9 R_{\mathrm{E}}\right)$ on the dawnside to the dayside and then back to the tail. Geotail was in the magnetosphere during about $20 \mathrm{~h}$ starting on 22 October 1999 on 09:00 UT. The satellite was on the duskside $\left(Y_{\mathrm{gsm}}\right.$ about $\left.8 R_{\mathrm{E}}\right)$ moving towards nightside below the equatorial plane $\left(Z_{\mathrm{gsm}}\right.$ about $\left.-4 R_{\mathrm{E}}\right)$.

\section{Modeling results: external magnetic field variations along satellite orbits and the Dst index}

Both storm events have been previously modeled with the event-oriented model; the results have been presented in Ganushkina et al. (2004) and Kalegaev et al. (2005), where a detailed comparison was made between the model magnetic field and the observed field along the satellite orbits. Here we present new comparisons between the modeled and observed field at geostationary satellites, GOES 8, 9 and 10 for SWMF models, TS04 (Tsyganenko and Sitnov, 2005) model and together with the previously presented event-oriented model (Ganushkina et al., 2004; Kalegaev et al., 2005). We use two principally different modeling approaches (eventoriented and SWMF) to further analyze the magnetospheric configuration and current systems in the present paper.

Figure $3 \mathrm{a}$ shows the three components of the magnetic field observed at GOES 8 (panels 1-3 from top) and GOES 9 
November 7, 1997, 00-10 UT
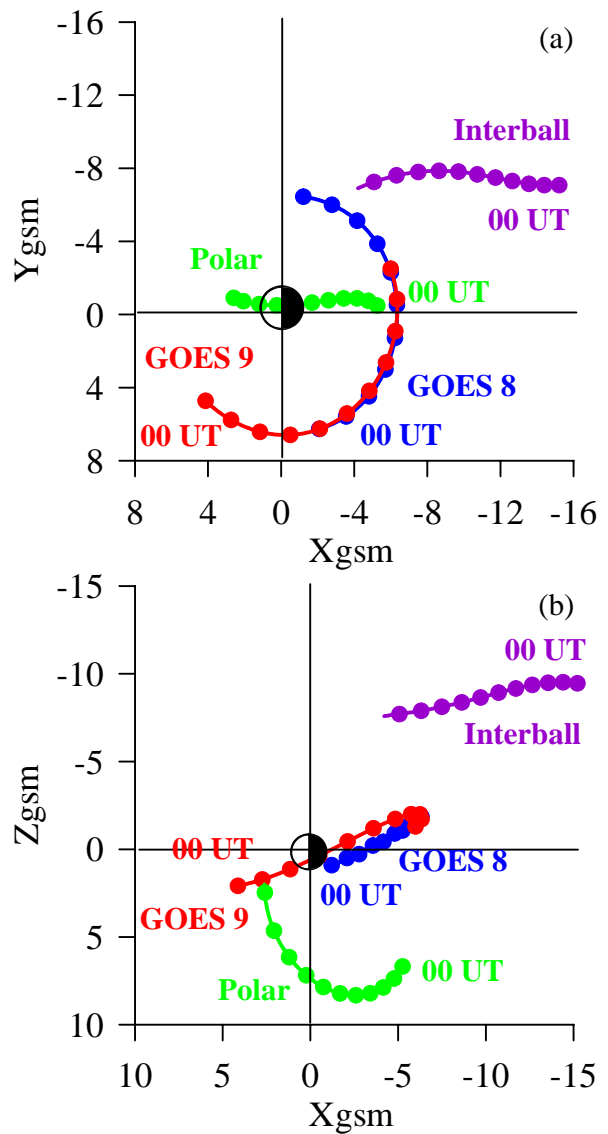

October 22, 1999, 00-12 UT

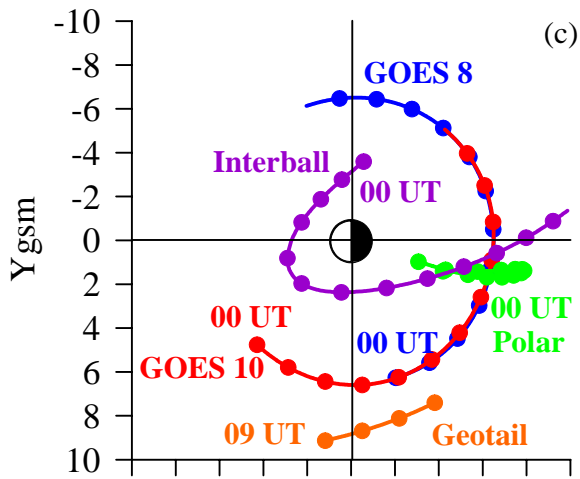

$\begin{array}{lllllllllllll}10 & 8 & 6 & 4 & 2 & 0 & -2 & -4 & -6 & -8 & -10\end{array}$ Xgsm

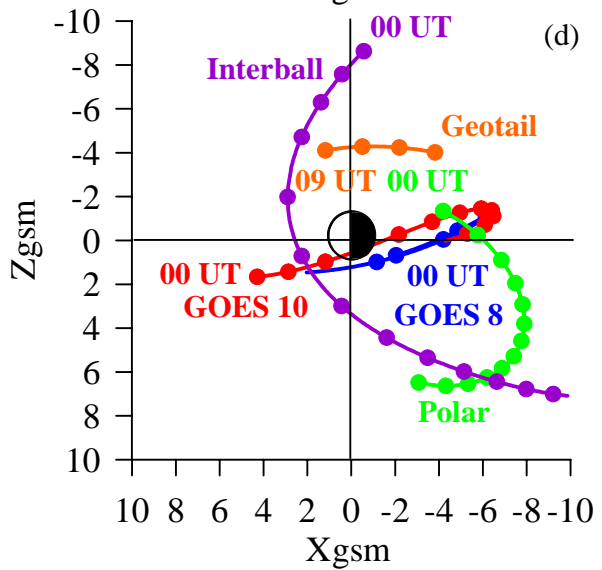

Fig. 2. Evolution of orbits of satellites such as GOES 8 (blue), GOES 9 or 10 (red), Polar (green), Geotail (orange) and Interball Tail (purple), in the equatorial and noon-midnight meridian plane, during (a) 00:00-10:00 UT on 7 November 1997 and (b) 00:00-12:00 UT on 22 October 1999, which corresponds to storm main phase and early recovery phase. The time interval between two dots on the satellite orbits is $1 \mathrm{~h}$.

(panels 4-6) satellites (black) during the moderate 6-7 November 1997 storm event together with the modeled magnetic field using the event-oriented magnetic field model (red). The magnetic field (green) from the Tsyganenko and Sitnov TS04 model (Tsyganenko and Sitnov, 2005) is shown here as a reference. The bottom panels present the Dst index, or more precisely, the SYM-H index (black) and the modeled Dst using the event-oriented magnetic field model (pink line). The Dst index can be computed from the eventoriented model by evaluating the external field at the Earth's surface (see Ganushkina et al., 2004). Figure 3b has the same format as Fig. 3a but shows the magnetic field output from the SWMF model (blue) and the Dst index obtained from SWMF model (bottom panel, purple). The Dst index from the SWMF model was calculated by solving the BiotSavart integral for all the currents encompassed in the SWMF simulation domain from $2.5 \mathrm{Re}$ outward, and taking the $\mathrm{z}$ component of the magnetic field disturbance at the origin. The simulation domain is defined in the volume bounded in x from $-224 R_{\mathrm{E}}$ to $32 R_{\mathrm{E}}$, y from $-128 R_{\mathrm{E}}$ to $128 R_{\mathrm{E}}$ and $\mathrm{z}$ from $-128 R_{\mathrm{E}}$ to $128 R_{\mathrm{E}}$. The influence of the currents induced below the Earth's surface was taken into account by reducing the observed Dst by 30\% (Häkkinen et al., 2002).

As described in Ganushkina et al. (2004) and Kalegaev et al. (2005), the event-oriented model was able to reproduce the $B_{z}$ component at geostationary orbit quite well overall and not badly for substorm-associated changes. Modeled $B_{z}$ components also track quite closely the observed ones also at Polar, Geotail and Interball Tail satellites (not shown). On the other hand, the model could not fit well the observed large variations in the $B_{x}$ component. The large observed $B_{x}$ values imply the existence of intense currents that can be either field-aligned (when $B_{x}$ component is azimuthal near dawn and dusk) or perpendicular (when $B_{x}$ component is radial near midnigh and noon). Moreover, there could be an even stronger compression of the magnetotail lobes than that represented by the magnetopause current intensification in the model. Note that all of these data are actually used in the 
November 6-7, 1997
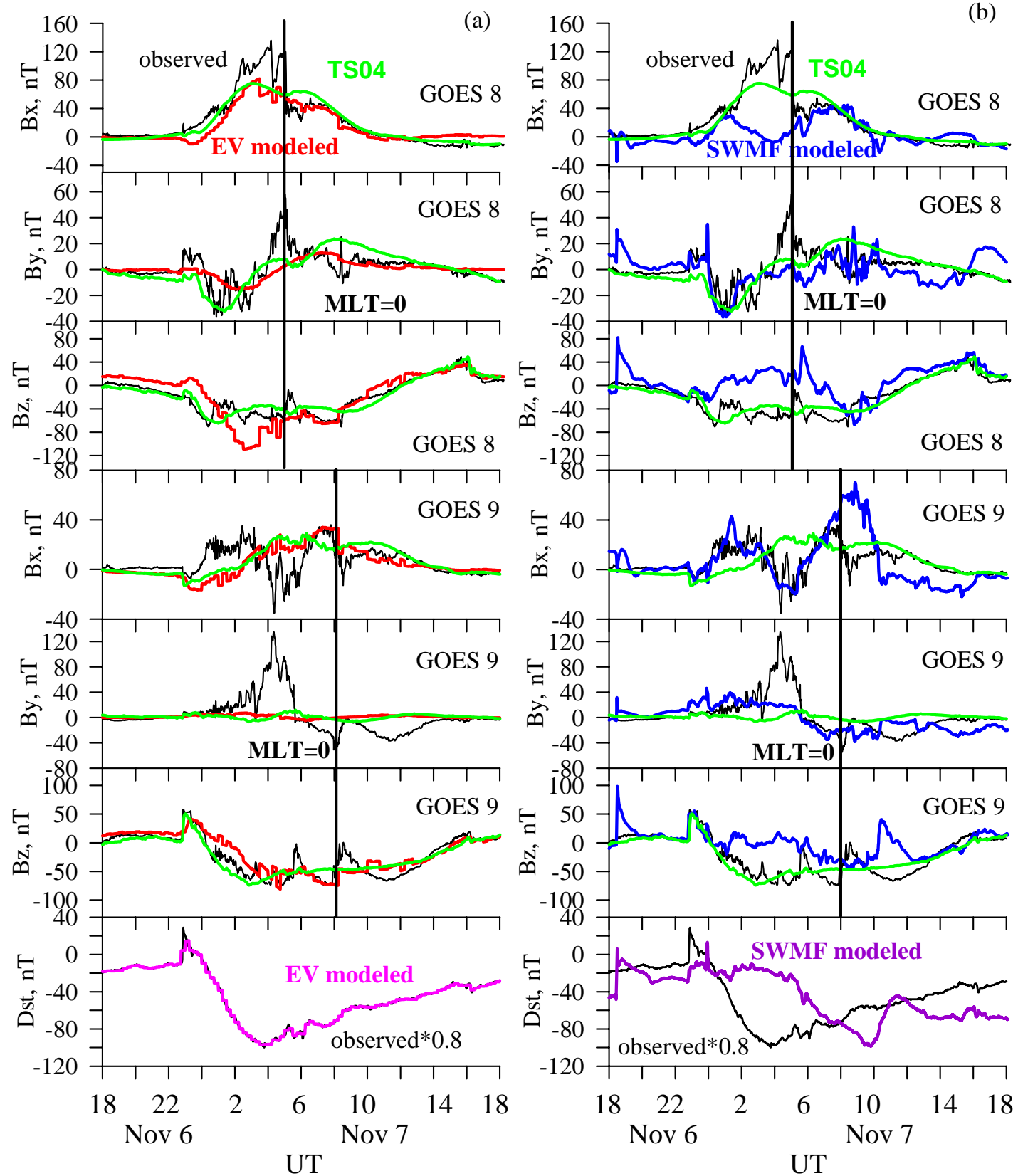

Fig. 3. Modelling results for 6-7 November 1997 storm event: Comparison between the external magnetic field modeled by (a) the eventoriented magnetic field model (red) and by (b) the magnetic field output from SWMF magnetospheric modeling (blue) and the magnetic field observed at GOES 8 (first three panels) and GOES 9 (next three panels) satellites (black) and modeled by Tsyganenko and Sitnov TS04 magnetic field model (green). The bottom panels present the Dst index, SYM-H observed (black line) and modeled using the event-oriented magnetic field model (pink) and the magnetic field output from SWMF magnetospheric modeling (purple). The influence of the currents induced below the Earth's surface was taken into account by reducing the observed Dst by 30 percent.

parameter fitting within the event-oriented model, however, they are each weighted differently in the routine.

The SWMF magnetic field output showed mixed comparisons with the GOES and Dst data. It reproduces the $B_{y}$ component at most satellite locations, although a few of the larger variations in $B_{y}$ were not reproduced. The SWMF model also gets the correct trend for the $B_{z}$ component, and the dayside values for $B_{z}$ are quite good. However, the magnitude of the $B_{z}$ decrease across the nightside is not as large as that observed at any of the satellites. For the $B_{x}$ 
October 21-23, 1999
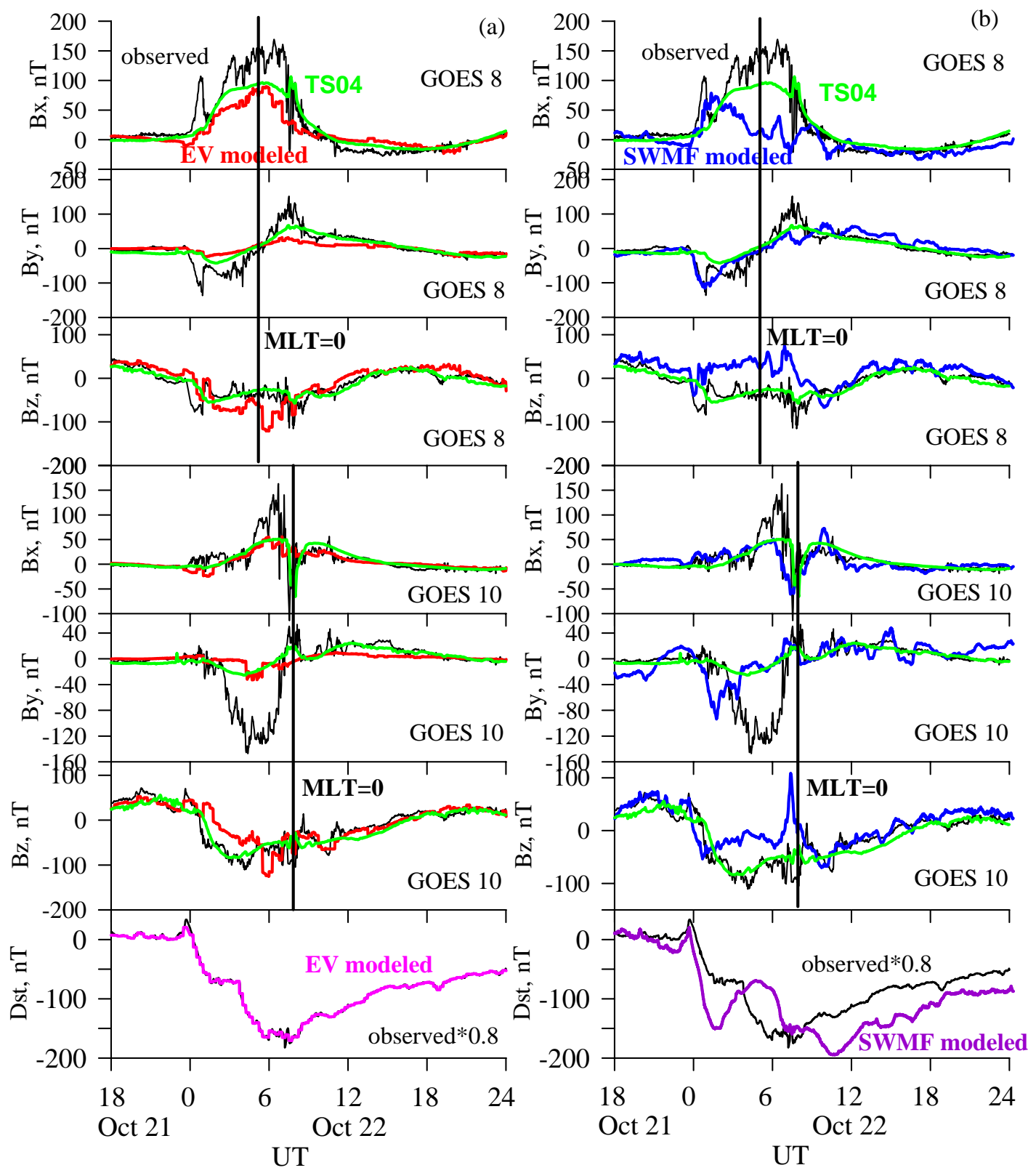

Fig. 4. Modeling results for 21-23 October 1999 storm event, the same as in Fig. 3.

component, again the trend was correct, showing increases and decreases in roughly the correct locations and times, except usually not to observed magnitudes of the peaks. In addition, the $B_{x}$ component peak seen by GOES 8 between 02:00 and 05:30 UT on 7 November 1997 was not reproduced at all. This peak was observed around midnight local time and resulted from compression of the entire magnetosphere including the tail. The solar wind dynamic pressure was increased during this time interval to about $8 \mathrm{nPa}$. It seems that the SWMF magnetopause and tail currents were not strong enough or close enough during this period. At the same time, the smaller peak in $B_{x}$ observed at GOES 9 at dusk in the beginning of the day of 7 November was better tracked. The following similar peak at 06:00-08:00 UT, when GOES 9 was almost at midnight, was actually overestimated by the SWMF. It seems that the magnetopause currents in the SWMF modeling have a delayed reaction to the solar wind pressure increase. The differences between observations and the SWMF results in $B_{y}$ indicates an underestimation of the field-aligned currents in the SWMF representation for this event. The $B_{z}$ overestimated indicates that the SWMF field is too dipolar in the nightside, that is, near-Earth part of the tail current is too weak. 
The Tsyganenko and Sitnov TS04 model (Tsyganenko and Sitnov, 2005) was especially developed for the storm-time geomagnetic field, using magnetic field data taken during 37 major storms. The approach used in this model was to derive from the data the temporal variation of all major current systems, such as the magnetopause current, tail current, symmetric and partial ring currents, and field-aligned currents, assuming that each current system has its individual relaxation timescale and residual quiet-time strength. Each current system is driven by its own variable, calculated as a time integral of a combination of the solar wind density, speed, and magnitude of the southward component of the IMF. The contributions to the total field depend on the history of the external driving of the magnetosphere during a storm.

As can be seen in Fig. 3, the TS04 model gives roughly the same accuracy of the $B_{x}$ and $B_{y}$ components on both GOES 8 and 9 during moderate storm on 6-7 November 1997. It does not show significantly better representation than the event-oriented model. The peaks in the $B_{x}$ component and variations in the $B_{y}$ component are not reproduced particularly well, especially the short-time-scale changes in the magnetic field. The TS04 $B_{z}$ components follow more closely the observed ones, but no changes associated with substorms are present. These differences are expected, because fast temporal changes are not included in the formulation of the TS04 model.

Figure 4 presents the observed and modeled components of the magnetic field and Dst index, similarly to Fig. 3, for the intense 21-23 October 2001 storm event. During the intense storm on 21-23 October 1999 the peaks in $B_{x}$ component were also observed at both GOES 8 and 10 satellites. Similar trends are found to those mentioned above for the moderate storm. For the event-oriented model, the $B_{z}$ magnetic field components are well reproduced, followed by slightly less accurate representations of $B_{y}$ and then $B_{x}$. This shows an underestimation of the field-aligned currents in the inner magnetosphere. The SWMF results showed mixed accuracy when compared with the GOES data. The $B_{x}$ trends were in the right direction, but not large enough. The SWMF $B_{x}$ was only half of the observed one in the large $B_{x}$ increase which GOES 8 recorded at 02:00-08:00 UT on 22 October with a peak at 02:00 MLT. There was a large peak of about $40 \mathrm{nPa}$ in solar wind dynamic pressure around 07:00 UT that influenced the $B_{x}$ component peak at GOES 8 located just past midnight in local time. GOES 10, located five hours earlier in local time, observed a peak in the $B_{x}$ component around 07:00 UT, which was not reproduced by SWMF field. After that the $B_{x}$ decreased at midnight, and the SWMF field followed that decrease. As for the moderate storm event, the SWMF magnetopause currents during the intense storm were not strong enough or close enough to the spacecraft. Similarly, the $B_{y}$ component is mostly correct, except for an observed negative excursion at GOES 10 at dusk. The SWMF $B_{z}$ component was also like the moderate storm, with good dayside values and the nightside values in the right direc- tion but the perturbation was not large enough. So, again, the representation of field-aligned and tail currents in the SWMF model was underestimated.

The performance of the TS04 model for the intense storm on 21-23 October 1999 does not differ much from that of the moderate storm on 6-7 November 1997. The $B_{z}$ component is very similar to the GOES measurements (except for short-time-scale variations), and the $B_{x}$ and $B_{y}$ components follow the observed trends but show much smaller perturbations than those measured by GOES. As with the eventoriented model, this shows an underestimation of the fieldaligned currents in the near-Earth region.

The bottom panels of Fig. 3 and Fig. 4 present the modeled and observed Dst indices. As was mentioned in previous studies (Ganushkina et al., 2004; Kalegaev et al., 2005), the event-oriented model is able to follow Dst very closely, even overlap, for both storm events. Note that the observed value is used as a fitting parameter in the routine. For the SWMF, the modeled Dst index gives a reasonable magnitude of the Dst minimum, but the wrong timing for this peak during both storms. For the 7 November 1997 storm, the SWMF Dst has the peak around 10:00 UT, about $6 \mathrm{~h}$ later than that in the observed Dst. Later, there is another decrease in the modeled Dst after a short (about an hour) recovery. The Dst profile modeled with SWMF is rather unlike the observed one.

For the intense storm on 21-23 October 1999, the SWMF modeled Dst index is much closer to the observed one. On 22 October 1999 the Dst index first decreased to about $-90 \mathrm{nT}$ around 02:00 UT. The modeled Dst dropped about half an hour earlier to about $-150 \mathrm{nT}$. The second drop and minimum in the observed Dst was about $-190 \mathrm{nT}$ around 06:00 UT. This second dip in Dst was not modeled correctly by the SWMF. When the observed Dst drops, the modeled one continues to recover and drops again only after about 05:00 UT reaching the minimum of $-200 \mathrm{nT}$ around 11:00 UT. The modeled Dst recovers with about $50 \mathrm{nT}$ offset to the observed recovery profile.

\section{Modeling results: storm-time changes in the current systems}

Using the magnetic field output from both the event-oriented and the SWMF approaches, we compute the current densities and integral current in the magnetosphere. Analyzing their time evolution, we are able to study the storm-time changes in the two main current systems, the ring current and the tail current and determine their individual contributions to the total Dst index.

The upper row of images in Fig. 5 presents the distributions of current densities (in $\mathrm{nA} / \mathrm{m}^{2}$ ) in the equatorial plane (at $Z_{\mathrm{gsm}}=0$ ) obtained from the event-oriented modeling at four times during the moderate storm on 6-7 November 1997: initial phase (23:15 UT on 6 November), main phase (03:45 UT on 7 November), and recovery phase (12:15 UT 

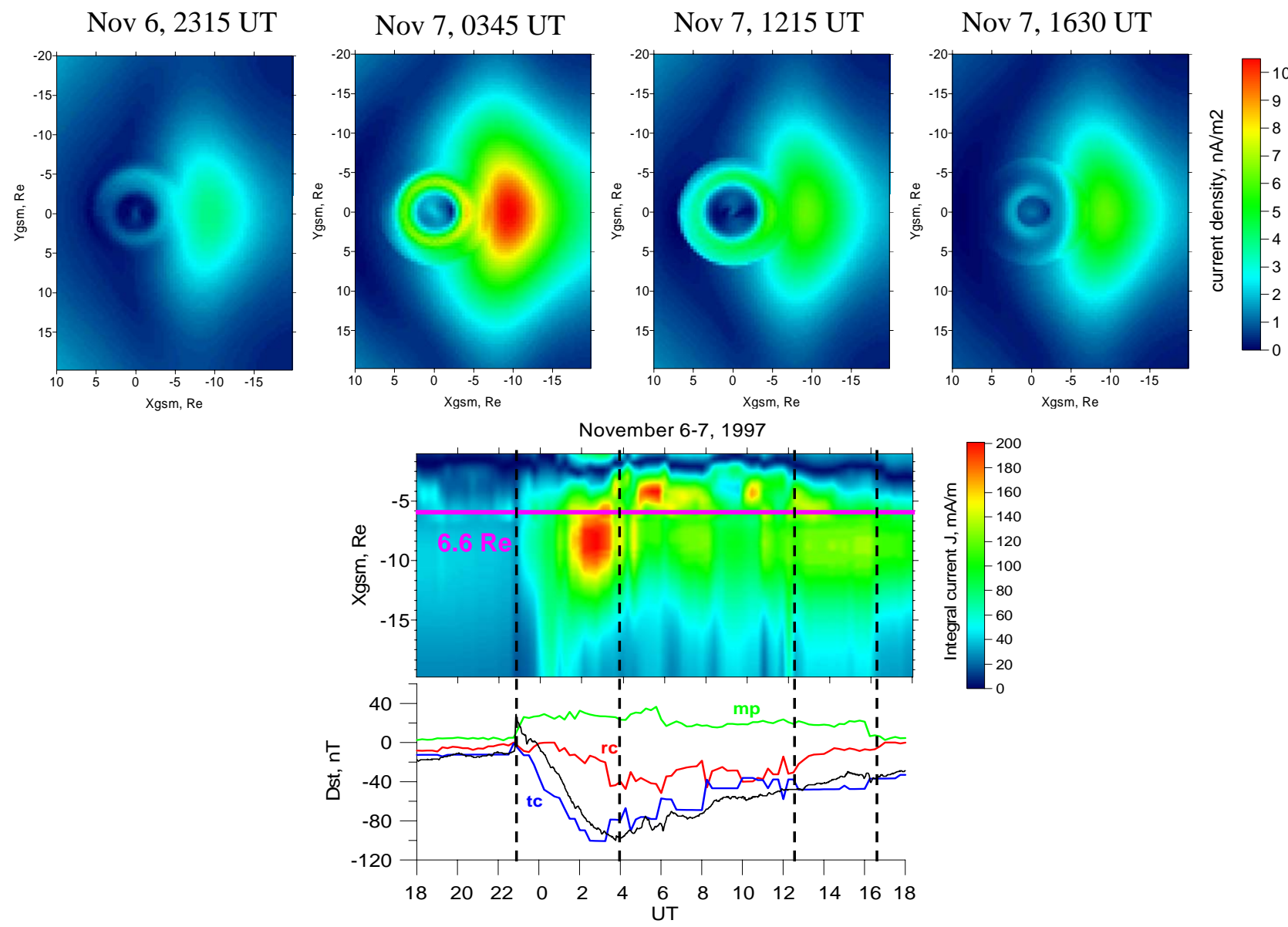

Fig. 5. Upper part: Distributions of current densities (in $\mathrm{nA} / \mathrm{m}^{2}$ ) in the equatorial plane obtained from the event-oriented modeling at four time moments during moderate 6-7 November 1997 storm: initial phase (23:15 UT on 6 November), main phase (03:45 UT on 7 November), and recovery phase (12:15 UT and 16:30 UT on 7 November). Lower part, upper panel: Current (in $\mathrm{mA} / \mathrm{m}$ ) integrated across the current sheet thickness (over $Z_{\mathrm{gsm}}$ from $-4 R_{\mathrm{E}}$ to $4 R_{\mathrm{E}}$ ) as a function of UT and $X_{\mathrm{gsm}}$ at midnight. Lower part, lower panel: Model contributions from the ring current (red), tail current (blue) and magnetopause currents (green) to the observed Dst index (black line).

and 16:30 UT on 7 November). Note that the Tsyganenko T89 model, used as the basic model here, does not include an explicit magnetopause.

The bottom figure, upper panel, in Fig. 5 shows the current integrated across the current sheet thickness $\left(Z_{\mathrm{gsm}}\right.$ from $-4 R_{\mathrm{E}}$ to $\left.4 R_{\mathrm{E}}\right)$ as a function of UT and $X_{\mathrm{gsm}}$ at midnight. The color coding gives the current per unit length in $X_{\mathrm{gsm}}$ in $\mathrm{mA} / \mathrm{m}$. The purple horizontal line indicates the position of the geostationary orbit at $6.6 R_{\mathrm{E}}$. This figure does not provide information about the asymmetry, but it shows how the azimuthal current evolves along the $X_{\mathrm{gsm}}$-axis. The lower panel presents the contributions from the ring current (red), tail current (blue) and magnetopause currents (green) to the observed Dst index (black).

During the moderate storm the tail current plays a key role. It develops first with the Dst drop and it is more intense (with current density of more than $10 \mathrm{nA} / \mathrm{m}^{2}$ ) than the ring current (about $6-7 \mathrm{nA} / \mathrm{m}^{2}$ ). The ring current develops later and re- mains enhanced, while the tail current decreases following the Dst recovery (7 November, 12:15 UT). The current density distributions obtained from the event-oriented model do not show a well defined dawn-dusk asymmetry. There is no significant partial ring current in the model results.

Similar to Fig. 5, Fig. 6 shows the current densities in the equatorial plane obtained from the SWMF modeling approach for the moderate 6-7 November 1997 storm (upper row). In contrast to the distributions from the event-oriented modeling, here the magnetopause currents and their intensifications during the main and recovery storm phases are clearly seen. The near-Earth currents are also much more variable both in space and time compared to the event-oriented model results. This is expected because this is a first-principle dynamical model while the event-oriented code has specified locations for each current. The upper part of the bottom figure shows the integrated current as a function of UT and $X_{\mathrm{gsm}}$ at midnight. The lower panel presents the observed (black) 

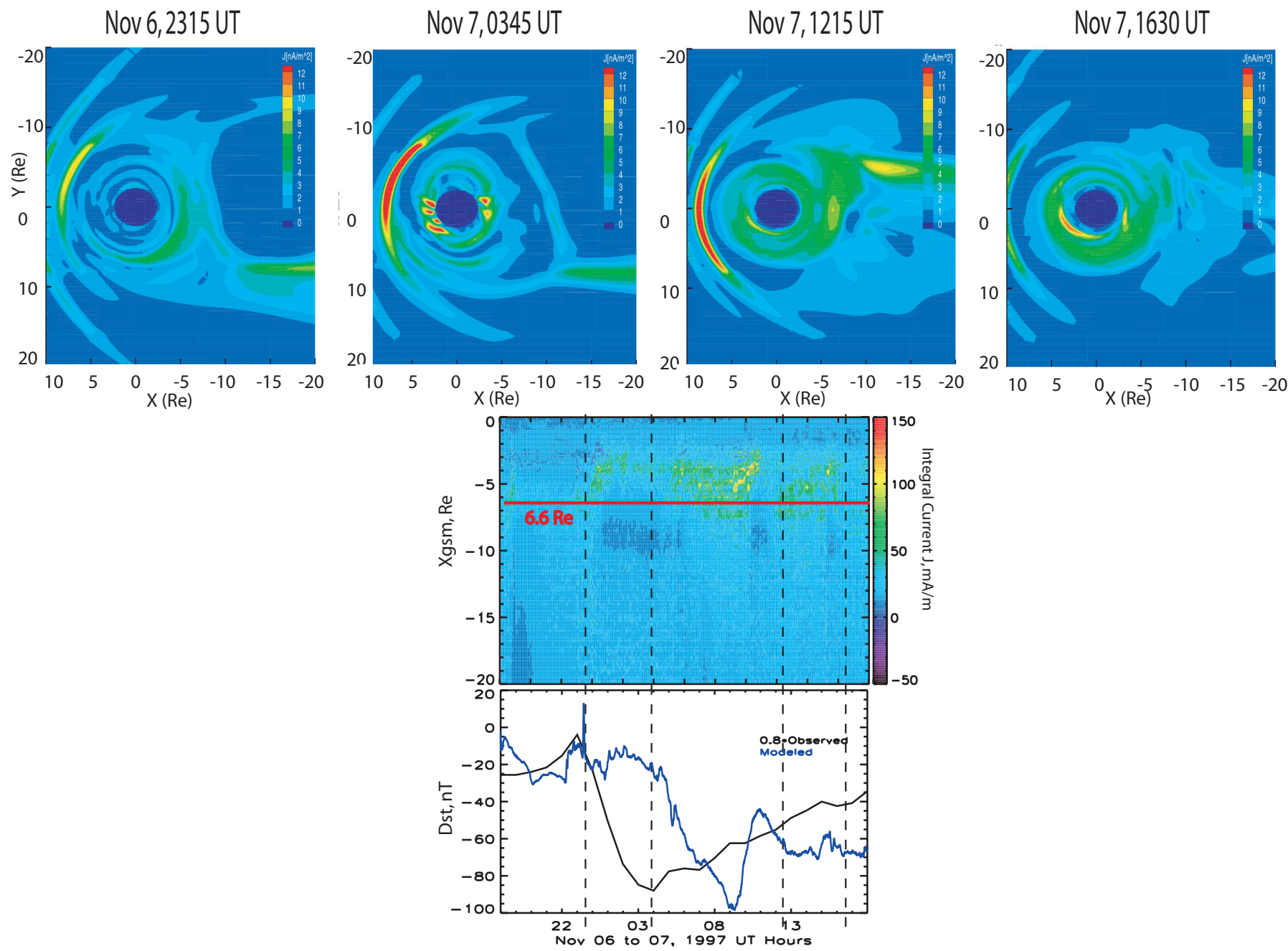

Fig. 6. Similar to Fig. 5 but for the output from the SWMF modeling.

and modeled Dst index (purple). It is quite difficult to extract the exact contributions from SWMF modeled current systems to the Dst index, since the current systems are not defined explicitly and can not be separated without the introduction of artificial assumptions regarding the regions where they flow.

Even without this explicit accounting of the contributions of specific current systems to Dst, we can examine these plots and qualitatively interpret their influence. It should be noted that for this storm, the SWMF timing of the storm peak is late by $6 \mathrm{~h}$. At the observed storm peak, the SWMF results do not show any significant tail current. The ring current is symmetric with average current density of $5 \mathrm{nA} / \mathrm{m}^{2}$, and the tail current is very weak at the distances between -5 to $-15 R_{\mathrm{E}}$. Later, however, the modeled partial ring current greatly intensifies and an azimuthal current develops between 3 and $7 R_{\mathrm{E}}$ (with a peak value of about $9 \mathrm{nA} / \mathrm{m}^{2}$. The ring current becomes more intense and broad, and a tail current develops at $-10 R_{\mathrm{E}}$. Even late in the recovery phase of the storm, the modeled inner magneospheric current system is not a symmetric ring, but rather still exhibits large local time asymmetries.

The upper row in Fig. 7 shows the distributions of current densities in the equatorial plane obtained from the eventoriented modeling in the same format as Fig. 5 at four times during the intense storm on 21-23 October 1999: initial phase (23:15 UT on 21 October), main phase (02:45 UT and 07:15 UT on 22 October), and recovery phase (22:15 UT on 22 October). The upper part of the bottom figure presents the integrated current and the lower part shows the modeled contributions from the current systems to the observed Dst index.

Note that the scale is different for the intense storm, where the current densities are two times larger than for the moderate storm, and the integral current is three times larger than those for the moderate storm. The tail current still develops first with the Dst drop but does not increase further with the Dst deepening. At the same time, the ring current increases 
Oct 21, 2315 UT

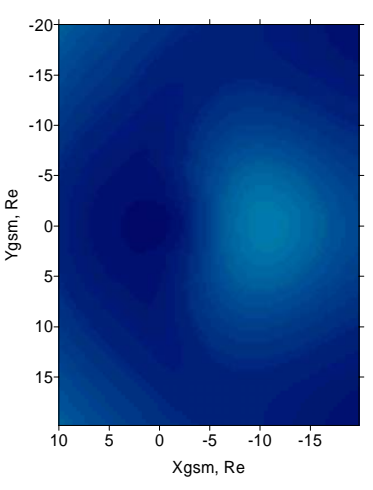

Oct 22, 0245 UT

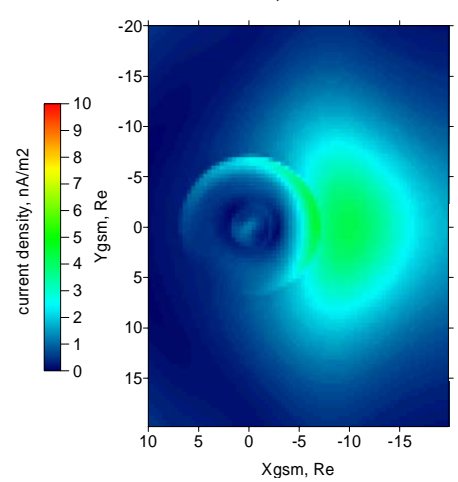

Oct 22, 0715 UT

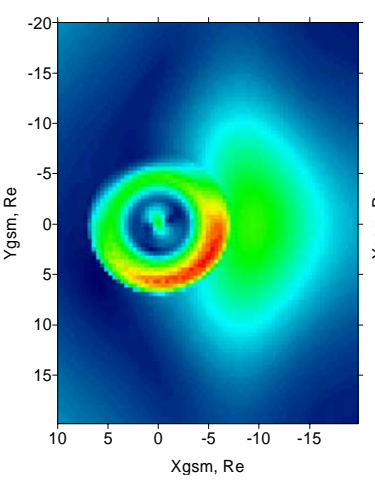

Oct 22, 2215 UT

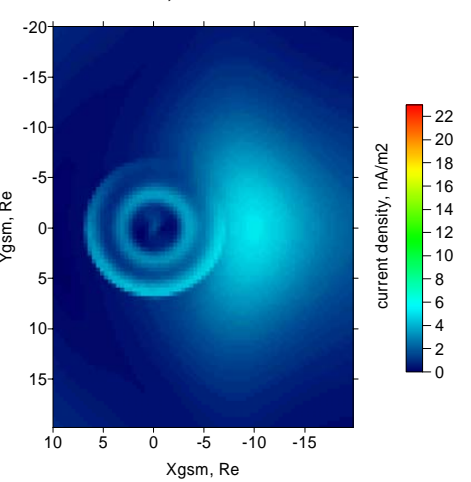

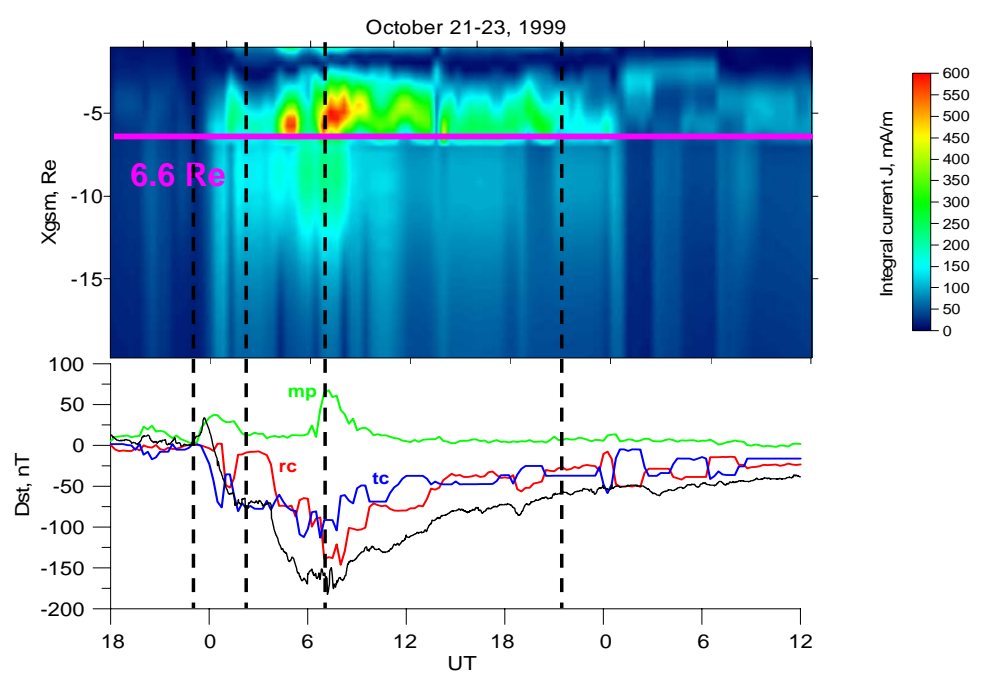

Fig. 7. Same as Fig. 5 but for intense 21-23 October 1999 storm.

and becomes the dominant contributor to the Dst index during the storm main phase and during several hours of the recovery phase. The well-defined dawn-dusk asymmetry with an intense partial ring current is present. Modeling using the event-oriented approach suggests that the appearance of a strong asymmetric ring current depends on storm strength.

The current densities obtained using the SWMF modeling approach for the intense 21-23 October 1999 storm are quite different from those for the moderate storm. As can be seen in Fig. 8, the storm main phase is characterized by an intense, asymmetric ring current with current densities of more than $20 \mathrm{nA} / \mathrm{m}^{2}$, which is comparable to the event-oriented model results. These ring current intensifications correspond to the Dst dips in the modeled profile. The ring current becomes symmetric during the recovery phase. Still, there is no tail current seen at 02:45 UT on 22 October, and tail current is rather weak at 07:15 UT. For the intense storm, the SWMF approach reproduces the storm-time behavior of the ring current much better but misses the tail current dynamics again. The resulting better representation of the ring current and Dst profile may arise from the less important role of the tail current during intense storms.
The patchiness of the inner magnetospheric currents from the SWMF results is reminiscent of the small-scale structure of the partial ring current seen in the results of Liemohn et al. (2005) and Liemohn and Brandt (2005). In those studies, this structure resulted from the nonlinear feedback of the ring current on the inner magnetospheric electric field. As particles are injected close to the Earth from the tail, the closure of this new partial ring current through the ionosphere alters the electric potential pattern in the mid-latitude ionosphere. The net result is that injected particles modify the electric field in a way that tries to break up the newly injected plasma peak. This same nonlinear feedback is evident here in the BATSRUS-RCM-RIM coupling within the SWMF.

\section{Magnetic field distortions produced by current systems}

Typically, it is assumed that on the nightside, inside $6 R_{\mathrm{E}}$, the magnetic field is close to dipole. While this is true for quiet periods, during disturbed times the dipole approximation is no longer accurate. The external magnetic field becomes 

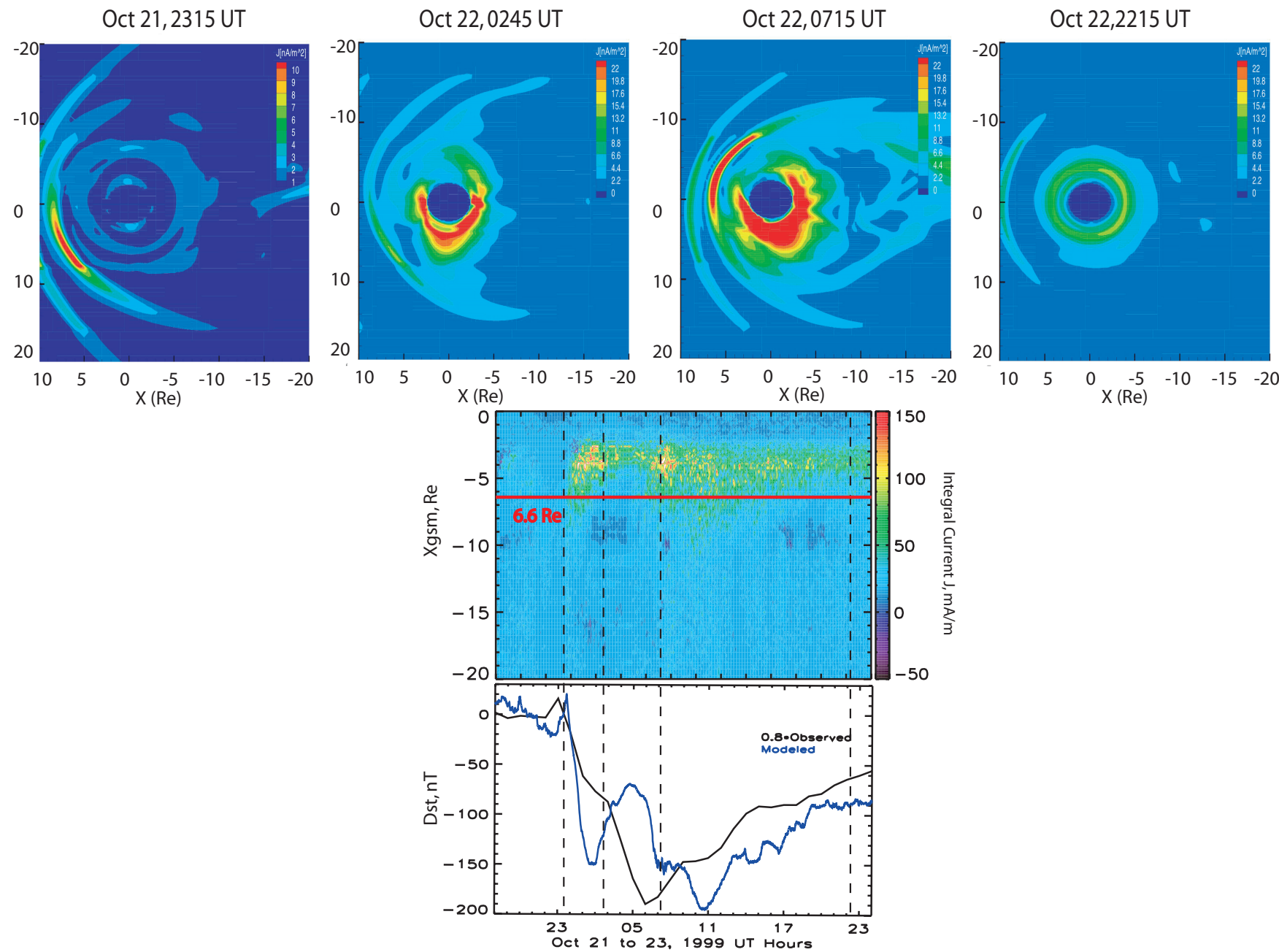

Fig. 8. Same as Fig. 6 but for intense 21-23 October 1999 storm.

comparable in magnitude to the dipole field at these distances. Figure 9 presents the distortions of the inner magnetospheric external magnetic field, resulting from stormtime current systems, as isolines of percentages from a dipole field $\left(100 \% \times \frac{B_{\text {ext }}}{B_{\text {dipole }}}\right)$ for the 6-7 November 1997 moderate storm. Reaching $100 \%$ would mean that $B_{\text {ext }}=B_{\text {dipole }}$ and over $100 \%$ means that $B_{\text {ext }}$ is larger that $B_{\text {dipole. The up- }}$ per row shows the percentages computed using the eventoriented model for the same four times during that storm as in the previous section: (a) initial phase, (b) main phase, and (c-d) recovery phase. During the initial phase (Fig. 9a), the external field sources produce only about $10 \%$ compared to the dipole field. During the storm main phase (Fig. 9b, storm maximum) the external magnetic field is about $30 \%$ of the dipole value at $4 R_{\mathrm{E}}$ and $80 \%$ of the dipole value at $6 R_{\mathrm{E}}$ at midnight. During the recovery phase (Fig. 9c, d) the contribution from the external field becomes smaller. As can be seen, there is no pronounced asymmetry in the isolines. Taking into account the above analysis of current distribution and evolution (Fig. 5), the tail current is the most important current system from this model for this moderate storm.

The lower row shows the field percentages computed using the SWMF approach for the same four times during the 6-7 November 1997 moderate storm. Here, the situation is quite different: the external field contribution becomes smaller during the storm main phase (Fig. 9f) than during the initial phase (Fig. 9e) because of the late timing of the storm in the model results. At midnight at $6 R_{\mathrm{E}}$ the external contribution is $20 \%$ and $40 \%$, respectively. The absence of significant tail currents during the storm main phase (Fig. 6) in the SWMF representation makes the magnetic field too dipolar. This was also noted when comparing the SWMF magnetic field with GOES measurements (Fig. 3). Stretching of the magnetic field lines due to the appearance of the tail and partial ring currents during the recovery phase (Fig. 6g) results in the magnetic field becoming less dipolar, and most likely closer to reality during this interval. 


\section{Event-oriented modeling, \% from dipole field}
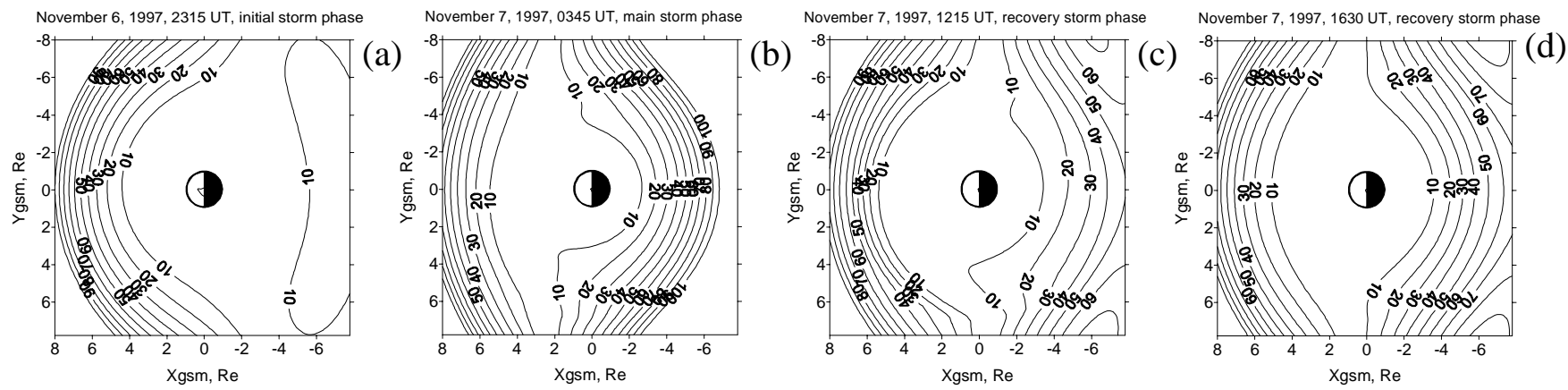

SWMF modeling, \% from dipole field
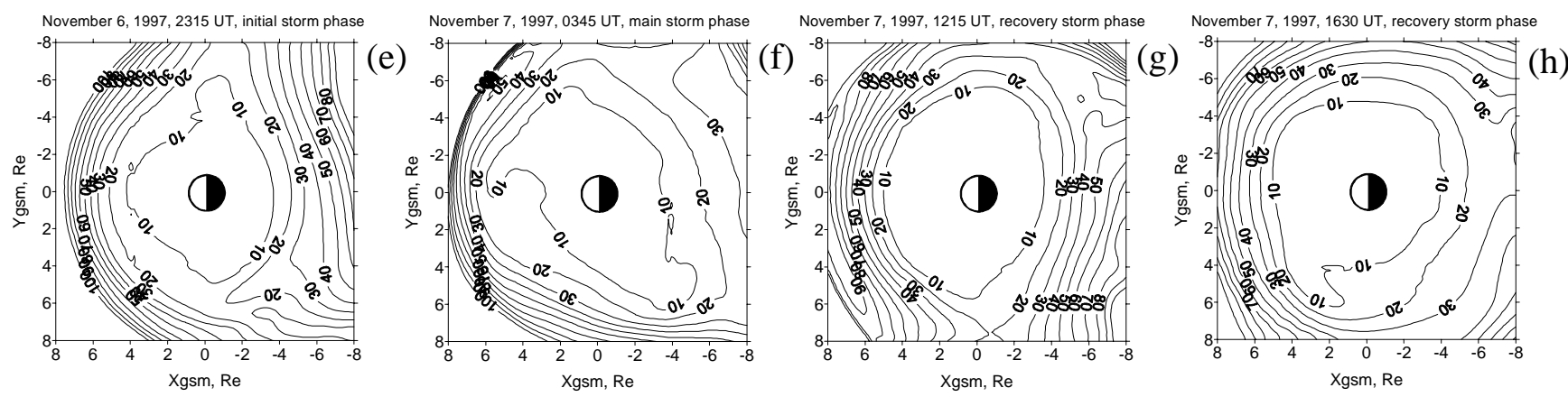

Fig. 9. Distortions of inner magnetosphere external magnetic field by the storm-time current systems as isolines of percentages from a dipole field $\left(100 \% \times \frac{B_{\text {ext }}}{B_{\text {dipole }}}\right)$ for 6-7 November 1997 moderate storm computed using the event-oriented model (a-d) and SWMF model (e-h).

Figure 10 shows, in similar format as Fig. 9, the isolines of percentages $100 \% \times \frac{B_{\text {ext }}}{B_{\text {dipole }}}$ for the 21-23 October 1999 intense storm. The upper row shows the percentages computed using the event-oriented model and lower row using the SWMF modeling approach for four times during the storm as in previous section: $(a, e)$ initial phase, $(b-c, f-g)$ main phase, and $(\mathrm{d}, \mathrm{h})$ recovery phase.

According to estimates obtained using the event-oriented model, during the first minimum in Dst (Fig. 10b) the magnetic field lines are very stretched. The external field contribution reaches $90 \%$ at $6 R_{\mathrm{E}}$ and $40 \%$ at $4 R_{\mathrm{E}}$ at midnight. These findings here are dramatic with the dipole approximation breaking down, in that the magnetic field at $6 R_{\mathrm{E}} \mathrm{RE}$ can become 10 times weaker than the dipole field. As seen in Fig. 7, this model found that the tail current was the main contributor to the Dst index and it is the tail current that distorts the dipole magnetic field at this time. At the storm maximum (Fig. 10c) a clear asymmetry in the isolines can be seen with a maximum $80 \%$ contribution from the external field rotated duskward to around 21:00 LT at about $4 R_{\mathrm{E}}$. The magnetic field lines are less stretched at $6 R_{\mathrm{E}}$, since at that moment the ring current is the main contributor to the Dst index and it is the main current distorting the dipole field.
Percentage isolines obtained from the SWMF modeling also show the asymmetric, irregular pattern during the storm main phase (Fig. 10f, g). The distortions of $50 \%$ at $4 R_{\mathrm{E}}$ and $70 \%$ at $6 R_{\mathrm{E}}$ come from the increased, asymmetric ring current (Fig. 8). The tail current was not particularly large for this storm either, so the magnetic field is too dipolar as can be seen also in Fig. 4.

\section{Discussion and conclusions}

Model results for two storm events, one moderate storm on 6-7 November 1997 with Dst minimum about $-120 \mathrm{nT}$ and one intense storm on 21-23 October 1999 with Dst minimum about $-250 \mathrm{nT}$ were compared. Magnetic field changes in the inner magnetosphere were obtained using two principally different approaches, the event-oriented model (Ganushkina et al., 2002, 2004) and the coupled codes, namely, the Global Magnetosphere (GM), Inner Magnetosphere (IM), Ionospheric Electrodynamics (IE), within the Space Weather Modeling Framework (SWMF), (Toth et al., 2005). In addition, the Tsyganenko and Sitnov TS04 (Tsyganenko and Sitnov, 2005) magnetic field model was used as a reference model. For both events we presented (1) the magnetic field 


\section{Event-oriented modeling, \% from dipole field}
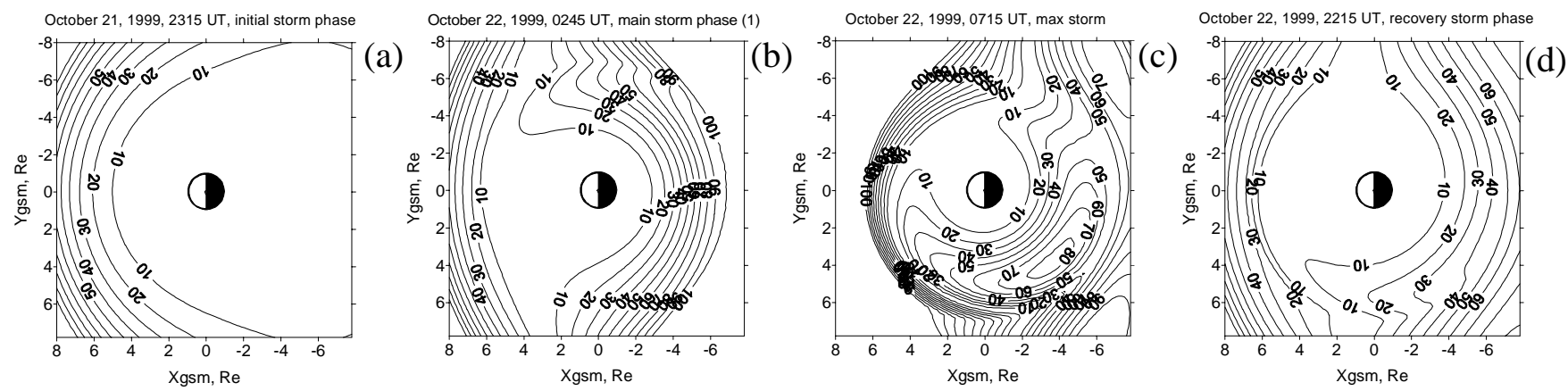

\section{SWMF modeling, \% from dipole field}
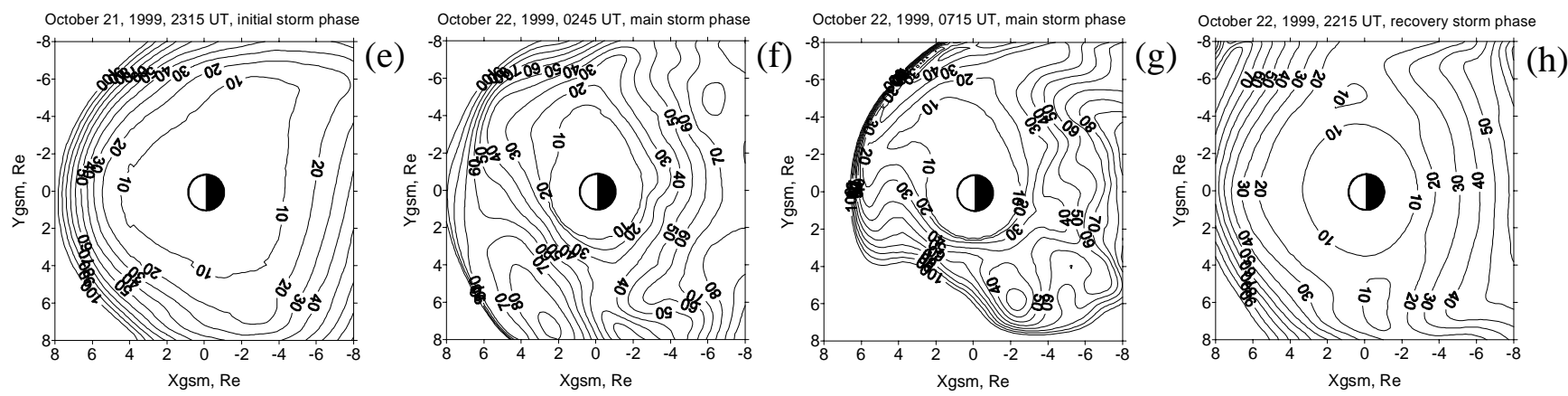

Fig. 10. Same as Fig. 9 but for intense 21-23 October 1999 storm.

variations along the GOES 8,9 and 10 satellite orbits together with the comparison to observations, (2) the evolution of equatorial current densities and integral currents along the $X_{\mathrm{gsm}}$-axis midnight meridian, (3) the contributions from different current systems to the Dst index for the event-oriented approach, and (4) the evolution of distortions of the dipole field by the external storm-time magnetic field.

The new insights from this study are found where the two modeling approaches agree on the current system responsible for the magnetic field distortion during one or both of these storms. We can also learn from the discrepancies, but these are less revealing, as it is unclear which of the two models (if either) is correct. When they agree in their similarities or differences with the data, then conclusions can be inferred about the real magnetospheric dynamics and current flows. With this in mind, the conclusions are as follows:

1. The two modeling approaches agree that the partial/symmetric ring current dominates during the intense storm. The larger solar wind perturbation during the intense storm injected particles deeper into the inner magnetosphere than during the moderate storm event. The storm main phase is characterized by an intense, asymmetric ring current symmetrizing during the recovery phase, and the tail current is relatively weak. Intense storm produces better representation of the ring current and Dst profile,which may be associated with the weaker tail current. The conclusion is that the intense storm resulted from a more substantial partial ring current during the main phase and a large, long-lasting symmetric ring current during the recovery phase.

2. Neither modeling approaches was able to reproduce properly all the variations in the $B_{x}$ and $B_{y}$ components observed at geostationary orbit by GOES satellites during these storms. These magnetic field components were distorted by the magnetopause and fieldaligned currents, and, therefore, this underestimation of the magnetic perturbations indicate that one or both of these current systems are too small in both modeling approaches. It is clear that the magnetopause current intensification in the event-oriented model was not large enough. Furthermore, this model does not include a separate representation of field-aligned currents and, therefore, this model cannot independently vary magnetic field contributions from field-aligned currents. For the SWMF approach, the magnetopause currents were most likely not strong enough for this period. Moreover, the magnetopause currents in SWMF model had a delayed reaction to the solar wind pressure increase (Fig. 3). Furthermore, there is most likely insufficient field-aligned currents in SWMF representation. 
The TS04 model, especially developed for storm-times, gave a similarly accurate representation of the observed magnetic field (but not particularly better than either model). The inference of this finding is that the magnetopause current, field-aligned currents, and/or partial ring current are actually larger than those predicted by these models.

For example, if the partial ring current in the eventoriented model is diverted into the ionosphere by the Region 2 field-aligned currents, for the modeled storms we have the following estimates for maximum magnitude of R2 FACs: during moderate 6-7 November 1997 storm R2 FAC $I_{\max }=1.5 \mathrm{MA}$, during intense $21-$ 23 October 1999 storm R2 FAC $I_{\max }=5.5$ MA. For TS04 model (Tsyganenko and Sitnov, 2005) the corresponding values are 1.6 MA and 1.7 MA, respectively. The behavior of current systems differs in the event-oriented and TS04 models (Ganushkina et al., 2004; Kalegaev et al., 2005). In the TS04 model there is no significant change in R2 FAC during intense storm. The model gives the dominant contribution from the tail current to the Dst index during intense storms too. Also the partial ring current is smaller than the symmetric ring current.

3. The event-oriented model reproduces best the $B_{z}$ component at geostationary orbit, including the substormassociated changes. The $B_{z}$ component is overestimated by the SWMF field compared to the measurements on GOES satellites on the nightside, even with the IM module, which increases the inner magnetosphere currents from the pure MHD approach.

In general, the results from SWMF depend on the grid resolution. It is very hard to accurately resolve everything, and using a finer mesh invariably changes the results. Previous studies by De Zeeuw et al. (2004) and Zhang (2007) have compared results from different model settings within the SWMF. In the present paper we are using a grid that provides reasonably gridconverged results without being computationally prohibitive.

The $B_{z}$ components modeled with TS04 follow more closely the observed ones but the changes associated with substorms are not well reproduced. This implies that substorms greatly contribute to the short-time-scale variations of the nightside magnetic field topology.

4. According to results from the event-oriented model, the tail current plays a key role during the moderate storm and also very important during the intense storm. It develops first with the Dst drop and it is more intense than the ring current. The ring current develops later and stays increased, while the tail current decreases following the Dst recovery. Setting the outer boundary at $6.6 R_{\mathrm{E}}$ in the ring current models can lead to underestimation of modeled Dst due to absence of tail current effects. The timing of the Dst time series for the moderate storm from the SWMF was late by $6 \mathrm{~h}$, and thus the current system analysis for this storm is difficult to interpret.

5. Comparison between two different modeling approaches is a useful tool for validation of firstprinciples-based representations of the Earth's magnetosphere (such as that from the SWMF) and empirical models (such as event-oriented or Tsyganenko models) in terms of magnetic field and currents systems during storm times.

Acknowledgements. The authors gratefully acknowledge the support of this work by NASA through grants NNG05GM48G, NNX07AL88G, and NNX08AQ15G, by NSF through grant ATM0802705, and by the LANL-IGPP minigrant program. We thank K. Ogilvie and R. Lepping for the use of WIND data in this paper, World Data Center C2 for Geomagnetism, Kyoto, for the provisional $\mathrm{AE}, \mathrm{Kp}$ and Dst indices data. The data were obtained from the Coordinated Data Analysis Web (CDAWeb). Natalia Ganushkina's work was partly supported by the Academy of Finland. We thank T. Pulkkinen for very useful discussions.

Topical Editor R. Nakamura thanks I. Dandouras and another anonymous referee for their help in evaluating this paper.

\section{References}

Alexeev, I. I., Kalegaev, V. V., Belenkaya, E. S., Bobrovnikov, S. Y., Feldstein, Y. I., and Gromova, L. I.: Dynamic model of the magnetosphere: Case study for January 9-12, 1997, J. Geophys. Res., 106, 5683-25693, 2001.

Bame, S. J., McComas, D. J., Thomsen, M. F., et al.: Magnetospheric Plasma Analyzer for Spacecraft with Constrained Resources, Rev. Sci. Instr., 64, 1026-1033, 1993.

Chen, M. W., Liu, S., Schulz, M., Roeder, J. L., and Lyons, L. R.: Magnetically self-consistent ring current simulations during the 19 October 1998 storm, J. Geophys. Res., 111, A11S15, doi:10.1029/2006ja011620, 2006.

De Zeeuw, D. L., Sazykin, S., Wolf, R. A., Gombosi, T. I., Ridley, A. J., and Tóth, G.: Coupling of a global MHD code and an inner magnetospheric model: Initial results, J. Geophys. Res., 109, A12219, doi:10.1029/2003JA010366, 2004.

Ganushkina, N. Y., Pulkkinen, T. I., Kubyshkina, M. V., Singer, H. J., and Russell, C. T.: Modeling the ring current magnetic field during storms, J. Geophys. Res., 107(A7), SMP 3-1, 1092, doi:10.1029/2001JA900101, 2002.

Ganushkina, N. Yu., Pulkkinen, T. I., Kubyshkina, M. V., Singer, H. J., and Russell, C. T.: Long-term evolution of magnetospheric current systems during storms, Ann. Geophys., 22, 1317-1334, 2004, http://www.ann-geophys.net/22/1317/2004/.

Ganushkina, N. Yu., Pulkkinen, T. I., and Fritz, T.: Role of substorm-associated impulsive electric fields in the ring current development during storms, Ann. Geophys., 23, 579-591, 2005, http://www.ann-geophys.net/23/579/2005/.

Ganushkina, N., Pulkkinen, T. I., Liemohn, M., and Milillo, A.: Evolution of the proton ring current energy distribution dur- 
ing April 21-25, 2001 storm, J. Geophys. Res., 111, A11S08, doi:10.1029/2006JA011609, 2006.

Gombosi, T. I., Tóth, G., De Zeeuw, D. L., Hansen, K. C., Kabin, K., and Powell, K. G.: Semirelativistic magnetohydrodynamics and physics based convergence acceleration, J. Comput. Phys., 177, 176-205, 2002.

Harel, M., Wolf, R. A., Reiff, P. H., Spiro, R. W., Burke, W. J., Rich, F. J., and Smiddy, M.: Quantitative simulation of a magnetospheric substorm, 1, Model logic and overview, J. Geophys. Res., 86, 2217-2241, 1981.

Hilmer, R. V. and Voigt, G.-H.: A magnetospheric magnetic field model with flexible current systems driven by independent physical parameters, J. Geophys. Res., 100, 5613-5626, 1995.

Huang, C.-L., Spence, H. E., Lyon, J. G., Toffoletto, F. R., Singer, H. J., and Sazykin, S.L.: Storm-time configuration of the inner magnetosphere: Lyon-Fedder-Mobarry MHD code, Tsyganenko model, and GOES observations, J. Geophys. Res., 111, A11S16, doi:10.1029/2006JA011626, 2006.

Häkkinen, L. V. T., Pulkkinen, T. I., Nevanlinna, H., Pirjola, R. J., and Tanskanen, E. I.: Effects of induced currents on Dst and on magnetic variations at midlatitude stations, J. Geophys. Res., 107, SMP1-7, 1014, doi:10.1029/2001JA900130, 2002.

Jaggi, R. K. and Wolf, R. A.: Self-consistent calculation of the motion of a sheet of ions in the magnetosphere, J. Geophys. Res., 78, 2852-2866, 1973.

Janhunen, P.: GUMICS-3 A Global Ionosphere-Magnetosphere Coupling Simulation with High Ionospheric Resolution, in: Environment Modelling for Space-based Applications, Symposium Proceedings (ESA SP-392), ESTEC Noordwijk, 18-20 September 1996, edited by: Burke, W. and Guyenne, T.-D., p. 233, 1996.

Jordanova, V. K., Farrugia, C. J., Thorne, R. M., Khazanov, G. V., Reeves, G. D., and Thomsen, M. F.: Modeling ring current proton precipitation by EMIC waves during the May 14-16, 1997, storm, J. Geophys. Res., 106, 7-22, 2001.

Jorgensen, A. M., Spence, H. E., Hughes, W. J., and Singer, H. J.: A statistical study of the global structure of the ring current, J. Geophys. Res., 109, A12204, doi:10.1029/2003JA010090, 2004.

Kalegaev, V. V., Ganushkina, N. Y., Pulkkinen, T. I., Kubyshkina, M. V., Singer, H. J., and Russell, C. T.: Relation between the ring current and the tail current during magnetic storms, Ann. Geophys., 23, 523-533, 2005, http://www.ann-geophys.net/23/523/2005/.

Kubyshkina, M. V., Pulkkinen, T. I., Ganushkina, N. Yu., Partamies, N.: Magnetospheric currents during sawtooth events: Eventoriented magnetic field model analysis, J. Geophys. Res., 113, A08211, doi:10.1029/2007JA012983, 2008.

Le, G., Russell, C. T., and Takahashi, K.: Morphology of the ring current derived from magnetic field observations, Ann. Geophys., 22, 1267-1295, 2004, http://www.ann-geophys.net/22/1267/2004/.

Lemon, C., Wolf, R. A., Hill, T. W., Sazykin, S., Spiro, R. W., Toffoletto, F. R., Birn, J., and Hesse, M.: Magnetic storm ring current injection modeled with the Rice Convection Model and a self-consistent magnetic field, Geophys. Res. Lett., 31, L21801, doi:10.1029/2004GL020914, 2004.

Liemohn, M. W. and Brandt, P. C.: Small-scale structure in the stormtime ring current, in: Inner Magnetosphere Interactions: New Perspectives from Imaging, AGU Monogr. Ser., vol. 159, edited by: Burch, J. L., Schulz, M., and Spence, H., p. 167, Am.
Geophys. Un., Washington, D.C., 2005.

Liemohn, M. W., Kozyra, J. U., Thomsen, M. F., Roeder, J. L., Lu, G., Borovsky, J. E., and Cayton, T. E.: Dominant role of the asymmetric ring current in producing the stormtime Dst*, J. Geophys. Res., 106, 10883-10904, 2001.

Liemohn, M. W., Ridley, A. J., Brandt, P. C., Gallagher, D. L., Kozyra, J. U., Mitchell, D. G., Roelof, E. C., and DeMajistre, R.: Parametric analysis of nightside conductance effects on inner magnetospheric dynamics for the 17 April 2002 storm, J. Geophys. Res., 110, A12S22, doi:10.1029/2005JA011109, 2005.

Lui, A. T. Y.: Inner magnetospheric plasma pressure distribution and its local time asymmetry, Geophys. Res. Lett., 30, 1846, doi:10.1029/2003GL017596, 2003.

Lyon, J. G., Fedder, J. A., and Mobarry, C. M.: The Lyon-FedderMobarry (LFM) global MHD magnetospheric simulation code, J. Atmos. Solar-Terr. Phys., 66, 1333-1350, 2004.

Mitchell, D. G., Hsieh, K. C., Curtis, C. C., Hamilton, D. C., Voss, H. D., Roelof, E. C., and Brandt, P. C:son: Imaging two geomagnetic storms in energetic neutral atoms, Geophys. Res. Lett., 28, 1151-1154, 2001.

Parker, E. N. and Stewart, H. A.: Nonlinear inflation of a magnetic dipole, J. Geophys. Res., 72, 5287-5293, 1967.

Pollock, C. J., Asamura, K., Balkey, M. M., et al.: Initial Medium Energy Neutral Atom (MENA) images of Earth's magnetosphere during substorms and storm-time, Geophys. Res. Lett., 28, 11471150, 2001.

Powell, K. G., Roe, P. L., Linde, T. J., Gombosi, T. I., and De Zeeuw, D. L.: A solution-adaptive upwind scheme for ideal magnetohydrodynamics, J. Comp. Phys., 153, 284-309, 1999.

Pulkkinen, T. I., Ganushkina, N. Yu., Tanskanen, E. I., Kubyshkina, M. V., Reeves, G. D., Thomsen, M. F., Russell, C. T., Singer, H. J. , Slavin, J. A., and Gjerloev, J.: Magnetospheric current systems during stormtime sawtooth events, J. Geophys. Res., 111, A11S17, doi:10.1029/2006JA011627, 2006.

Raeder, J., Wang, Y. L., Fuller-Rowell, T. J., and Singer, H. J.: Global Simulation of Magnetospheric Space Weather Effects of the Bastille Day Storm, Solar Phys., 204, 323-337, 2001.

Ridley, A. J. and Liemohn, M. W.: A model-derived description of the penetration electric field, J. Geophys. Res., 107, 1151, doi:10.1029/2001JA000051, 2002.

Ridley, A. J., Gombosi, T. I., and DeZeeuw, D. L.: Ionospheric control of the magnetosphere: conductance, Ann. Geophys., 22, 567-584, 2004, http://www.ann-geophys.net/22/567/2004/.

Shue, J.-H., Song, P., Russell, C. T., et al.: Magnetopause location under extreme solar wind conditions, J. Geophys. Res., 103, 17691-17700, 1998.

Toffoletto, F., Sazykin, S., Spiro, R., and Wolf, R.: Inner magnetospheric modeling with the Rice Convection Model, Space Sci. Rev., 107, 175-196, 2003.

Toth, G., Sokolov, I. V., Gombosi, T. I., et al.: Space Weather Modeling Framework: A new tool for the space science community, J. Geophys. Res., 110, A12226, doi:10.1029/2005JA011126, 2005.

Tsyganenko, N. A.: A magnetospheric magnetic field model with a warped tail current sheet, Planet. Space Sci., 37, 5-20, 1989.

Tsyganenko, N. A.: Modeling the Earth's magnetospheric magnetic field confined within a realistic magnetopause, J. Geophys. Res., 100, 5599-5612, 1995.

Tsyganenko, N. A.: A model of the near magnetosphere 
with a dawn-dusk asymmetry: 2. Parameterization and fitting to observations, J. Geophys. Res., 107, 1176, doi:10.1029/2001JA000220, 2002.

Tsyganenko, N. A. and Sitnov, M. I.: Modeling the dynamics of the inner magnetosphere during strong geomagnetic storms, J. Geophys. Res., 110, A03208, doi:10.1029/2004JA010798, 2005.

Tsyganenko, N. A. and Sitnov, M. I.: Magnetospheric configurations from a high-resolution data-based magnetic field model, J. Geophys. Res., 112, A06225, doi:10.1029/2007JA012260, 2007.

Tsyganenko, N. A., Singer, H. J., and Kasper, J. C.: Storm-time distortion of the inner magnetosphere: How severe can it get?, J. Geophys. Res., 108, 1209, doi:10.1029/2002JA009808, 2003.

Wolf, R. A.: Effects of ionospheric conductivity on convective flow of plasma in the magnetosphere, J. Geophys. Res., 75, 46774698, 1978.
Zaharia, S., Thomsen, M. F., Birn, J., Denton, M. H., Jordanova, V. K., and Cheng, C. Z.: Effect of storm-time plasma pressure on the magnetic field in the inner magnetosphere, Geophys. Res. Lett., 32, L03102, doi:10.1029/2004GL021491, 2005.

Zaharia, S., Jordanova, V. K., Thomsen, M. F., and Reeves, G. D.: Self-consistent modeling of magnetic fields and plasmas in the inner magnetosphere: Application to a geomagnetic storm, J. Geophys. Res., 111, A11S14, doi:10.1029/2006ja011619, 2006. Zhang, J.-Ch., Liemohn, M. W., De Zeeuw, D. L., Borovsky, J. E., Ridley, A. J., Sazykin, S., Thomsen, M. F., Kozyra, J. U., Gombosi, T. I., and Wolf, R. A.: Understanding storm-time ring current sources through data-model comparisons of a moderate storm, J. Geophys. Res., 112, A04208, doi:10.1029/2006JA011846, 2007. 